\title{
ORDEN GLOBAL, DESORDEN LOCAL: MINERÍA METALÍFERA, ACUMULACIÓN POR DESPOSESIÓN Y CONFLICTO EN EL NORTE NEUQUINO, ARGENTINA (1998-2017)
}

Sebastián Gómez Lende ${ }^{1}$

Resumen: Operando como vectores del orden global, la gran empresa transnacional y sus estrategias de acumulación por desposesión perturban el orden local al generar conflictos derivados de la coexistencia de racionalidades antagónicas respecto del uso del territorio. A la luz de estos supuestos, el artículo analiza el resurgimiento de la minería metalífera en el norte de la Provincia de Neuquén (Argentina) durante el período 1998-2017, utilizando para ello las categorías propuestas por la literatura. Los resultados muestran que las dinámicas expropiatorias de la firma global han producido un importante desorden local, plasmado en los nuevos cercamientos jurídico-territoriales, la privatización de tierra, subsuelo y recursos, la amenaza a formas de producción pre-capitalistas, el saqueo económico, la reestructuración del tejido socio-productivo local, la desapropiación ecológica y el avasallamiento de derechos. Palabras clave: Orden global y desorden local; Acumulación por desposesión; Minería metalífera; Provincia de Neuquén (Argentina)

\section{ORDEM GLOBAL, DESORDEM LOCAL: MINERAÇÃO METÁLICA, ACUMULAÇÃO POR DESAPROPRIAÇÃO E CONFLITO NO NORTE DA PROVÍNCIA DE NEUQUÉN, ARGENTINA (1998-2017)}

Resumo: Operando como vetores da ordem global, a grande empresa multinacional e suas estratégias de acumulação por desapropiação perturbam a ordem local ao gerar conflitos derivados da coexistência de racionalidades antagônicas respeito do uso do território. À luz destes supostos, o artigo analisa o ressurgimento da mineração metalífera no norte da Província de Neuquén (Argentina) durante o período 1998-2017, utilizando para isso as categorias propostas pela literatura. Os resultados mostram que as estratégias de acumulação da empresa global têm produzido uma importante desordem local, plasmado nos novos cercados jurídico-territoriais, a privatização da terra, o subsolo e os recursos, a ameaça às formas de produção pré-capitalistas, a pilhagem econômica, a expropriação ecológica e a subjugação de direitos.

Palavras-chave: Ordem global e desordem local; Acumulação por desapropiação; Mineração metalífera; Província de Neuquén (Argentina)

\footnotetext{
${ }^{1}$ Instituto de Geografía, Historia y Ciencias Sociales (IGEHCS). Consejo nacional de Investigaciones Científicas y Técnicas (CONICET)/Universidad Nacional del Centro de la Provincia de Buenos Aires (UNCPBA). Email: gomezlen@fch.unicen.edu.ar
} 


\title{
GLOBAL ORDER, LOCAL DISORDER: METAL MINING, ACCUMULATION BY DISPOSSESSION AND CONFLICT IN THE NORTH OF THE PROVINCE OF NEUQUÉN, ARGENTINA (1998-2017)
}

\begin{abstract}
Operating as vectors of the global order, the big transnational corporation and its strategies of accumulation by dispossession disrupt the local order by generating various conflicts derived from the coexistence of antagonistic rationalities regarding the use of the territory. In light of these assumptions, the article analyzes the resurgence of metal mining in the north of the Province of Neuquén (Argentina) during the period 1998-2017 by using the categories proposed by the literature. The results show that the expropriation dynamics of the global firm have produced an important local disorder, which is reflected in the new legal and territorial enclosures, the privatization of land, subsoil and resources, the threat to precapitalist forms of production, the economic plundering, the restructuring of the local socioproductive framework, the ecological expropriation, and the subjugation of human rights.
\end{abstract}

Keywords: Global order and local disorder; Accumulation by dispossession; Metal mining; Province of Neuquén (Argentina)

\section{INTRODUCCIÓN}

Operando como vectores del orden global, la gran empresa transnacional y sus modalidades de acumulación por desposesión perturban el orden local generando diversos conflictos derivados de la coexistencia de racionalidades antagónicas respecto del uso del territorio. A la luz de estos supuestos, este estudio de caso procura demostrar que el relativamente reciente resurgimiento de la minería aurífera en el departamento de Minas (Provincia de Neuquén, Argentina) y, más concretamente, en las localidades de Andacollo, Huinganco y Huaraco, constituye una expresión del orden global que, basada en la acumulación por desposesión, funciona como un elemento de desorden y desestructuración a escala local. Poniendo en juego una miríada de dinámicas expropiatorias, la lógica hegemónica del capital acaba alentando el desarrollo de contra-racionalidades por parte de los grupos subalternizados, lo cual decanta en la eclosión de agudos y diversos conflictos socioespaciales por el uso del territorio.

El artículo se estructura de la siguiente manera. En el primer acápite se desarrolla un apretado soporte teórico donde se discuten los conceptos de uso del territorio, orden global, desorden local, acumulación por desposesión y conflicto socio-espacial. Seguidamente se procede a la caracterización del universo de análisis, dando cuenta de sus principales rasgos históricos, productivos y sociales. Núcleo del trabajo, el tercer apartado se encuentra enteramente dedicado al análisis de las distintas formas de acumulación por desposesión que, reflejando la tensión entre orden global y desorden local, se derivan del resurgimiento reciente 
de la minería metalífera en el norte neuquino. Siguiendo los lineamientos propuestos por la literatura, se han considerado las siguientes dimensiones de análisis: a) la expropiación geográfica, la cual incluye los nuevos cercamientos jurídico-territoriales sobre los bienes comunes, la desintegración/(re)articulación del tejido socio-productivo local en función de las cadenas mundiales de valor del capital y las estrategias de precarización laboral y control/disciplinamiento social desplegadas por la gran empresa global; b) la expropiación político-económica, que contempla el papel de las prácticas clandestinas o fraudulentas del capital y el rol de los Estados nacional, provincial y municipal respecto de la legitimación de la acumulación por desposesión; y c) la expropiación ecológica, donde se abordan la mercantilización, apropiación diferencial y polución de la naturaleza, el avasallamiento de derechos colectivos y la erosión/destrucción de las formas de producción pre-capitalistas.

Asimismo, todas las variables mencionadas fueron atravesadas por el abordaje de los distintos conflictos socio-espaciales asociados, dando cuenta de los variados mecanismos de omisión, legitimación y protección que el aparato político proporcionó a la firma global. A modo de aclaración metodológica, vale señalar que se recurrió a fuentes de carácter estrictamente secundario, con marcado predominio de información provista por reportes periodísticos y portales web especializados y apoyo puntual de bibliografía general, dada la virtual ausencia de investigaciones académicas publicadas acerca de los impactos de la minería metálica en el universo de análisis considerado. Finalmente, se presentan las conclusiones del trabajo.

\section{MARCO TEÓRICO-CONCEPTUAL: USOS DEL TERRITORIO, ACUMULACIÓN POR DESPOSESIÓN Y CONFLICTOS SOCIO-ESPACIALES}

Siguiendo a Santos y Silveira (2001), el objeto de interés de la geografía no es el territorio en sí mismo, sino el territorio usado. A lo largo de los diversos períodos históricos, los usos del territorio propios de cada lugar revelan la tensión dialéctica entre el orden global y la razón local, es decir, entre lo organizacional y lo orgánico, entre las escalas superiores y el cotidiano, y entre el espacio reticular de flujos de las grandes empresas transnacionales y el espacio banal regido por la co-presencia, la vecindad, la socialización y la contigüidad espacial (SANTOS, 1996). Operando como vectores de la hegemonía del orden global, las firmas transnacionales constituyen un elemento de perturbación o desorden allí donde se 
instalan, debido tanto a los cambios funcionales y estructurales que imponen como al hecho de que su objetivo es egoísta y auto-referencial -el propio mercado mundial- (SANTOS, 1996; 2000). A raíz de esta tensión, el conflicto respecto de la lucha por el uso del espacio se torna inevitable, ganando una potencia y gravedad que suele ser directamente proporcional al grado de desigualdad socio-económica y asimetría de poder existente entre los agentes involucrados.

En los países periféricos, una dimensión medular de esta contradicción global-local se encuentra representada por distintas expresiones de lo que Harvey (2004) llama 'acumulación por desposesión'. Derivado de la noción marxista de acumulación primitiva u originaria (MARX, 1968), el concepto de acumulación por desposesión remite a todas aquellas modalidades de pillaje, fraude, depredación, violencia y rapiña que, amén de haber estado presentes en el acto histórico fundacional del capitalismo, se han convertido en una fuerza importante y permanente de la geografía histórica de dicho modo de producción, reeditando hasta nuestros días el pecado original del sistema (HARVEY, 2004; ROUX, 2007). De ahí el consenso en incluir en dicho concepto a todas aquellas prácticas que impliquen profundizar la privatización y mercantilización de lo común (DE ANGELIS, 2001) y/o jalar recursos y población ajenas a la lógica del capital hacia la órbita de este último (TETREAULT, 2013).

Alimentando la reproducción ampliada del capital en el centro del sistema, esta invasión legal y factual de los patrimonios de uso común y otros campos fronterizos a la matriz capitalista (GARIBAY OROZCO, 2010) conduce en la periferia al desplazamiento y eliminación de formas de producción pre-capitalistas -suprimiendo así rugosidades sociales y territoriales-, al despojo de activos públicos/estatales, a la expropiación de bienes comunes y al avasallamiento de derechos, estableciendo un orden de prioridades que beneficia a pocos actores -una producción limitada de racionalidad- y agrava la problemática social al no satisfacer las necesidades esenciales del resto -una producción ampliada de escasez(SANTOS, 1996; PATNAIK, 2005; HARVEY, 2004). Como resultado, la acumulación por desposesión suele desatar agudos conflictos espaciales que, derivados de los usos antagónicos que distintos agentes sociales pretenden asignarle a un mismo territorio (SÁNCHEZ, 1991), expresan la contradicción entre la racionalidad hegemónica del orden global -deseosa de conquistarlo todo- y las contra-racionalidades locales -donde los agentes afectados ensayan formas alternativas a la lógica dominante para simplemente sobrevivir- (SANTOS, 1996).

Dado que el fluido acceso a fuentes baratas y abundantes de materias primas es clave para asegurar la reproducción ampliada del capital en el centro del sistema, la relación entre 
acumulación por desposesión, modelo primario-exportador y usos extractivos del territorio se ha tornado cada vez más estrecha. Allí convergen la expropiación geográfica mercantilización y privatización de la tierra, nuevos cercamientos jurídicos y territoriales, desplazamiento de granjas familiares, expulsión de campesinos y aborígenes, apropiación imperial de bienes comunes, eliminación de formas de producción y consumo pre-capitalistas, etc.-, la expropiación político-económica -privatización y extranjerización del patrimonio público, desmantelamiento de los marcos de protección laboral, recomposición de la tasa de ganancia empresarial, transferencia de recursos hacia los centros mundiales de poder a través de reformas institucionales- y la expropiación ecológica -eliminación de mecanismos de protección ambiental, mercantilización de la naturaleza, apropiación diferencial y transferencia al exterior de bienes y servicios ecológicos, degradación del hábitat, etc.(MIDNIGHT NOTES COLLECTIVE, 2001; HARVEY, 2004; MACHADO ARÁOZ, 2010).

\section{CARACTERIZACIÓN HISTÓRICO-GEOGRÁFICA DEL UNIVERSO DE ANÁLISIS}

Situado en el extremo noroeste de la Provincia de Neuquén, en pleno norte patagónico argentino, el departamento Minas limita al norte y al oeste con la República de Chile, al sur con el departamento Norquín y al este con el departamento Chos Malal (Mapa 1). Su ciudad cabecera es Andacollo, enclavada en la confluencia de los ríos Varvaco y Lileo a 1.113 metros sobre el nivel del mar, a escasos 357 kilómetros del límite argentino-chileno (Mapa 2). Incluyendo a otros centros poblados como Las Ovejas, Huinganco, Los Miches, Manzano Amargo, Villa Nahueve, Varvarco y Huaraco, el departamento Minas es el epicentro de la llamada Zona Norte o Alto Neuquén, un área que, formada por los valles intermontanos que se extienden entre la Cordillera de Los Andes y la Precordillera del Viento, representa la faja de transición entre los Andes secos y los Andes nord-patagónicos húmedos, con inviernos regularmente lluviosos en las partes bajas y e intensas nevadas en las alturas (SILLA, 2010). 
Mapas 1 y 2 Provincia de Neuquén según división político-territorial (departamentos) y principales localidades del Departamento Minas

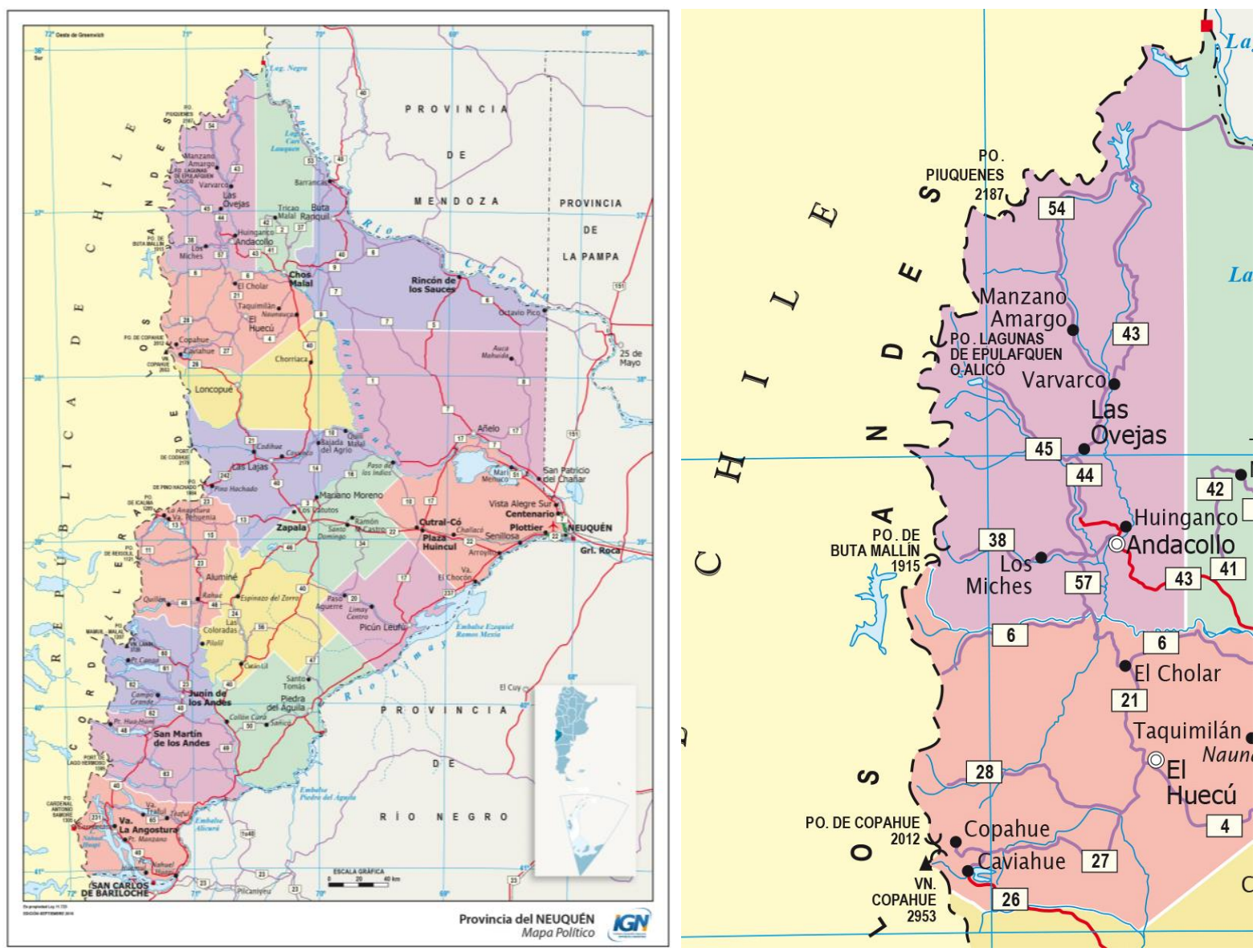

Fuente: IGN, s/f.

Originalmente poblado por aborígenes pehuenches y, en menor medida, mapuches, a comienzos del Siglo XIX el Alto Neuquén fue escenario de las últimas batallas de la independencia americana, funcionando entre 1813 y 1830 como refugio y base de operaciones para los grupos realistas españoles que, aliados a criollos e indígenas, procuraban abortar la emancipación chilena enfrentándose a las fuerzas militares del vecino país a través de montoneras, saqueos y guerrillas (SAPAG, 2012). Sofocados los últimos levantamientos rebeldes, la zona pasó a ser habitada por 600 estancieros chilenos que, en pacífica convivencia con pehuenches y criollos, desarrollaron la ganadería caprina, estableciendo un sistema de explotación basado en dos pisos ecológicos -la veranada en los altos cordilleranos y la 
invernada en los valles- que combinaba la alternancia entre trashumancia y sedentarismo con un patrón de poblamiento móvil y disperso (SILLA, 2010).

Este estado de cosas se prolongó hasta 1879, cuando la llamada "Campaña al Desierto" -paralela a la igualmente eufemística operación militar chilena de "Pacificación de la Araucanía"- llevó a cabo la matanza, arrinconamiento y expulsión de buena parte del remanente de los pueblos originarios aborígenes. Como resultado, el Ejército Nacional dispuso la creación de pueblos, estableció una capital como centro político de autoridad máxima y afianzó la frontera político-territorial andina hasta que el tratado argentino-chileno firmado en 1881 finalmente acabó ratificando la soberanía nacional sobre el área.

Con la "Campaña al Desierto" surgieron los primeros episodios de acumulación por desposesión en el Alto Neuquén. En un contexto donde la cosmovisión hegemónica de la época consideraba al nomadismo, la extrema movilidad espacial de criollos y mapuches y sus fuertes lazos culturales, parentales y comerciales con Chile como amenazas al orden interno (SILLA, 2010), el poder político impulsó la mercantilización y privatización parcial de la tierra a través del establecimiento de concesiones de pastaje y el cobro de arrendamiento para veranadas. Sin embargo, esos mecanismos no lograron impedir la continuidad de relaciones sociales de producción pre-capitalistas basadas en el absoluto predominio de las prestaciones de reciprocidad en detrimento del trabajo asalariado, la notable ausencia de grandes propietarios y el escaso o nulo nivel de jerarquización social (SAPAG, 2012).

Pocos años después, el Alto Neuquén se configuró en una de las principales quimeras del oro del sur argentino para los aventureros y cazadores de fortuna de la época. Con los primeros pedimentos de minas auríferas y argentíferas, llegaron también desde Chile los pirquineros o mineros artesanales para trabajar en los lavaderos de oro emplazados en el paraje Huaraco, a orillas del arroyo homónimo, todo lo cual decantó en 1883 en la fundación de la localidad de Andacollo ${ }^{2}$. Desde finales del Siglo XIX hasta 1956, diversas minas auríferas fueron explotadas por compañías norteamericanas -Corydon Peter Hall-, británicas The Neuquen Proprietary Gold Mine, Butler \& Virant- y argentinas -Minera Huaraco, Compañía Aurífera del Neuquén, Compañía Minera La Julia, etc.-, algunas de ellas gozando incluso de aceitados vínculos con el poder político provincial. El importante dinamismo

\footnotetext{
${ }^{2}$ Originariamente la localidad fue bautizada como Cañada del Durazno, hasta que en 1907 comenzó a ser llamada Andacollo por los propios pirquineros chilenos que participaron en su fundación, en honor a la Virgen de Andacollo, patrona de los mineros de la localidad homónima trasandina.
} 
alcanzado por Andacollo y la cercana localidad de Huinganco determinó que, hacia 1920, el departamento de Minas se convirtiera en el más poblado de Neuquén, concentrando el 12,6\% de la población provincial (BERTANI, 2011). El boom minero originó también los primeros episodios de devastación ambiental, como la extinción de los bosques nativos de lengas, cuya madera fue utilizada por las firmas mineras inglesas para apuntalar los socavones (NOYA, 2015).

La crisis sobrevino hacia mediados del Siglo XX, impulsada básicamente por dos factores: el cierre a partir de 1941 de los pasos cordilleranos por parte de la Gendarmería Nacional, lo cual determinó el bloqueo del comercio minero y ganadero del Alto Neuquén con destino a Chile; y el cese de operaciones en 1956 de Minera Huaraco, cuya clausura supuso el comienzo del derrumbe de la actividad extractiva en la región, que a partir de entonces comenzó a depender del escaso dinamismo inyectado por el Estado provincial. El cierre de la frontera chileno-argentino y la ausencia de vías de comunicación con el resto del país resultaron catastróficos, situación que fue parcialmente mitigada por el contrabando, práctica que se tornó frecuente frente al casi inexistente mercado de consumo local, la atractiva posibilidad de vender ganado en Chile a valores que duplicaban los precios domésticos (SAPAG, 2012) y la necesidad de drenar el exceso de caprinos para evitar la saturación de los campos de invernada y las consiguientes pérdidas económicas por mortandad animal y degradación del suelo. Quienes no se arriesgaron al contrabando acabaron emigrando, fenómeno alentado por la acción desarrollista del Estado -que en 1964 inició la construcción de un puente para unir a Andacollo con el resto de Neuquén- y el auge de la actividad petrolera y frutícola en el centro de la provincia (SILLA, 2010; SAPAG, 2012).

En la actualidad, el Alto Neuquén y, particularmente, el departamento de Minas, constituyen la región de menor nivel de desarrollo relativo de la provincia, con evidente persistencia de relaciones pre-capitalistas, fuerte éxodo demográfico, escasa cohesión interna y débil vinculación con el resto del territorio (COLANTUONO, 1995). De hecho, la única actividad económica dinámica es la minería metálica de exportación, que a finales de la década de 1990 resurgió con renovados bríos gracias a la extracción de oro y plata en las cercanías de Andacollo, desde entonces la única explotación metalífera de la provincia de Neuquén.

Según el último Censo Nacional de Población, Hogares y Viviendas realizado en 2010, la localidad de Andacollo albergaba en 2010 a sólo 2.627 habitantes, y el departamento 
Minas, a 7.235 -esto es, apenas el 1,4\% de la población neuquina- (INDEC, 2013), de los cuales buena parte correspondía a población rural dedicada al pastoreo trashumante que complementaba el ciclo de invernada y veranada con la agricultura de subsistencia y la inserción de algunos miembros del grupo familiar en el sector forestal y las agencias estatales (SAPAG, 2012). De hecho, el empleo público representaba el 69,75\% del mercado laboral local, con marcado protagonismo de la administración provincial $(43,7 \%)$ y municipal $(25,4 \%)$ (INDEC, 2013). La pobreza estructural alcanzaba al 13,5\% de los hogares superando la media tanto nacional $(9,1 \%)$ como provincial (10,4\%)- (DINREP, 2014), casi la tercera parte $(32,82 \%)$ de la población carecía de cobertura de salud y más de la mitad (58\%) de las viviendas poseía una conexión a los servicios de calidad no-satisfactoria, siendo básica en el $20,87 \%$ de los casos y directamente insuficiente en más de la tercera parte $(37,18 \%)$ (INDEC, 2013).

\section{MINERÍA METALÍFERA, ACUMULACIÓN POR DESPOSESIÓN Y CONFLICTO EN EL NORTE NEUQUINO. DEL ORDEN GLOBAL AL DESORDEN LOCAL}

La expropiación geográfica: cercamientos jurídico-territoriales, reestructuración del tejido socio-productivo local y conflicto laboral

Ciertamente, la relación entre minería metalífera y acumulación por desposesión en América Latina es tan estrecha como antigua. Su génesis se remonta al período colonial, cuando el dinamismo alcanzado por la extracción de plata y oro en los actuales territorios de Bolivia, México y Brasil supuso una formidable contribución al proceso de acumulación primitiva del capital en Europa (MARX, 1968; MANDEL, 1969). En la actualidad, la minería metálica continúa siendo clave para la reproducción del sistema capitalista debido a la constante demanda de oro para joyería y reserva monetaria, las importaciones chinas de cobre, la fiebre del litio para la producción de baterías recargables para teléfonos celulares, computadoras portátiles y automóviles eléctricos y la ya típica demanda de metales de uso industrial -cromo, plomo, níquel, manganeso, cadmio, zinc, etc.-. En un contexto signado por la escasez/agotamiento de reservas y/o el descenso de la ley de los metales en los principales países mineros (Estados Unidos, Canadá, Australia, Sudáfrica) y la mayor rigurosidad de las legislaciones ambientales en las naciones de origen de las empresas, la oleada de inversiones extranjeras mineras que durante el último cuarto siglo se ha abatido sobre América Latina y 
África debe ser interpretada como un emergente del proceso contemporáneo de apropiación neocolonial e imperial de recursos estratégicos oportunamente señalado por Harvey (2004).

En Argentina en general, y en Neuquén en particular, el boom minero gestado por el modelo neoliberal de la década de 1990, madurado durante la fase neo-desarrollista de comienzos del Siglo XXI y reconfirmado por la actual etapa de restauración iniciada a finales de 2015 ha producido nuevos cercamientos jurídico-territoriales sobre la tierra, el subsuelo y los recursos minerales en tanto que bienes comunes. Estos nuevos cercamientos se basan en la privatización y/o supresión de regímenes de propiedad comunal, colectiva o estatal, un fenómeno que, de acuerdo a la literatura especializada, constituye una de las principales herramientas de acumulación por desposesión del período histórico actual (HARVEY, 2004).

Abandonadas a mediados del Siglo XX, las minas auríferas de Andacollo permanecieron inactivas hasta que en 1976 la Corporación Minera del Neuquén Sociedad del Estado Provincial (CORMINE SEP) retomó la explotación de varios aluviones y comenzó a explorar las vetas Erika, Sofía y Julia, proceso que se extendió hasta 1989. No obstante, a partir de 1993 la nueva legislación formulada por el gobierno nacional para el sector minero alentó la radicación masiva de capitales extranjeros y prohibió expresamente al Estado intervenir en la actividad, salvo caso de asociación con inversores privados. Como resultado, CORMINE se vio obligada a llamar a licitación para ofrecer la concesión del Complejo Minero Andacollo, un área de 29.000 hectáreas constituida por varios depósitos polimetálicos, entre ellos las vetas subterráneas Sofía, Erika, Julia, Rosario, El Peludo, Buena Vista y Karina, ricas en plata y oro de alta $l^{2} y^{3}$, con presencia de cobre, zinc, azufre, plomo, hierro, arsénico, antimonio e insolubles y reservas superiores a las 200.000 toneladas (OCMAL, 2017).

Así pues, en 1998 el gobierno neuquino adjudicó por veinte años los yacimientos a Minera Andacollo Gold S.A. (MAGSA), una empresa que inicialmente estuvo controlada en un $70 \%$ por inversores chilenos (Asesoría e Inversiones Benjamín S.A.) y en un 30\% por la compañía minera canadiense Barrick Gold (ORTIZ, 2008), y que luego sufrió varios cambios en su composición accionaria (DIARIO RÍO NEGRO, 2015a). En 2010, cuando había transcurrido poco más de la mitad del plazo de concesión, el gobierno provincial prorrogó la misma por otra década. Cuando finalmente MAGSA abandonó la explotación a comienzos de

\footnotetext{
${ }^{3}$ La ley de los concentrados se estimaba en 426 gramos de oro y 510 gramos de plata por tonelada de roca.
} 
2015, el paralizado complejo minero retornó a manos del Estado neuquino, quien en 2017 lo cedió a la firma australiana Trident Southern Explorations por un plazo de 25 años ${ }^{4}$.

Si bien el régimen establecido fue de concesión y no de privatización propiamente dicha, en la práctica esto ha supuesto la expropiación absoluta de la tierra, el subsuelo y los recursos minerales; de hecho, el Código de Minería textualmente estipula que el derecho a explotar la mina es un auténtico derecho de propiedad exclusivo, perpetuo y transferible, permitiendo la venta y leasing del activo. Como resultado, la enajenación de tierras públicas, la extranjerización de los bienes comunes del patrimonio geológico para su posterior conversión en reservorios estratégicos destinados a la producción de commodities y el usufructo por parte de las corporaciones extranjeras del esfuerzo de exploración estatal llevado a cabo durante décadas previas -con la consiguiente anulación del riesgo minero privado- no ha significado otra cosa que el enriquecimiento corporativo a expensas del Estado vía la expropiación de activos públicos (PATNAIK, 2005). Asimismo, estos cercamientos cercenan los derechos de libre circulación territorial garantizados por la Constitución Nacional, en un marco donde los agentes privados se arrogan atribuciones similares a las de las fuerzas públicas de seguridad y estas últimas son cooptadas para pasar a operar como garantes de los intereses corporativos.

Evidenciando la capacidad de la gran empresa global de disponer sobre el territorio local, el resurgimiento de la minería metalífera en Andacollo revela otro dispositivo expropiatorio: la articulación del lugar a las cadenas mundiales de valor de las corporaciones transnacionales y la consiguiente (re)configuración del tejido socio-productivo regional en función de la dinámica de acumulación del capital. Según distintas fuentes, la producción de MAGSA ascendía a aproximadamente 9 toneladas anuales de concentrados de oro y plata que, valuados en alrededor de 6 millones de dólares, representaban el 2,51\% de las exportaciones provinciales (DIARIO RÍO NEGRO, 2009a; 2011; CAC, 2016). Dado que el proceso extractivo no generaba ningún encadenamiento productivo a escala local, el espacio reticular de flujos (SANTOS, 1996; 2000) o circuito espacial de producción (MORAES, 1988; SANTOS y SILVEIRA, 2001) de la firma global reproducía la típica lógica de la economía de enclave; de hecho, el concentrado mineral era enviado en bruto a Chile para ser separado y procesado en refinerías del país trasandino y de Perú, y luego (re)exportado a Alemania y otras naciones europeas, pese a las reiteradas promesas de la empresa de

\footnotetext{
${ }^{4}$ A diciembre de 2017, la nueva concesionaria aún no había iniciado la explotación del complejo minero.
} 
establecer una planta de refinación en Andacollo ${ }^{5}$ (DIARIO RÍO NEGRO, 2003; NOYA, 2015).

Tanto la racionalidad neocolonial de enclave como la configuración del espacio de flujos verticales de MAGSA se hallaban íntimamente asociadas a otro cercamiento jurídicoterritorial: el Tratado de Integración Minera entre Chile y Argentina, un acuerdo firmado en 1997 que independizó por cuarenta años a la Cordillera de los Andes de la jurisdicción administrativa de los respectivos gobiernos nacionales, permitiendo a las compañías mineras usufructuar las economías de escala y las ventajas logísticas asociadas al aprovechamiento conjunto de los recursos hídricos, la fuerza laboral y la infraestructura disponible sin necesidad de trasbordo -empalmes ferroviarios y puertos- a ambos lados de la faja cordillerana. Este gigantesco cercamiento -que se extiende a lo largo de 5.400 kilómetros, abarcando la décima parte del territorio argentino y la tercera parte del chileno (GIRAUD y RUZ, 2009)- ha creado una suerte de 'tercer país' gobernado por los intereses mineros y exento de controles aduaneros y fiscales, lo cual explica la fluidez con que MAGSA remesaba su producción a Chile. Por añadidura, y dado que los recursos hídricos son una variable clave para el desarrollo de la actividad minera metalífera, el tratado argentino-chileno ha implicado la privatización lisa y llana de la 'fábrica de agua dulce cordillerana' -esto es, las nacientes de los ríos- (ANTONELLI, 2010), generando otro fenómeno de cercamiento y despojo que será objeto de un análisis más pormenorizado en acápites posteriores de este trabajo.

En Andacollo, la racionalidad hegemónica del enclave minero exportador y su lógica de uniformización productiva han contribuido a suprimir la diversidad eco-territorial y sociocultural preexistente, en un contexto donde el modelo hegemónico opera como productor de ámbitos mono-culturales del capital (MACHADO ARÁOZ, 2010). Surge así una paradoja: por un lado, el empleo directo generado por la explotación minera ha sido más bien escaso, oscilando entre los 150 y los 280 operarios, manteniéndose por general por debajo del umbral de los 200 puestos de trabajo y representando en 2010 apenas el 2,13\% del mercado laboral departamental (VELÁZQUEZ, 2009; DIARIO LA MAÑANA DE NEUQUÉN, 2009; INDEC, 2013; DIARIO CLARÍN, 2014; DIARIO RÍO NEGRO, 2015b; NOYA, 2015); pero a su vez la empresa era percibida por los pobladores locales como el motor de la dinámica

\footnotetext{
${ }^{5} \mathrm{Si}$ bien la actual concesionaria ha efectuado anuncios similares, nada sugiere que dichas promesas se cumplan, teniendo en cuenta que, al igual que MAGSA, la base regional de operaciones de Trident Southern Explorations se encuentra en Chile.
} 
económica, a tal punto que los atemorizaba la reiterada amenaza esgrimida por la firma de abandonar la explotación ante conflictos laborales/ambientales (VELÁZQUEZ, 2009).

Podría argüirse que dicha contradicción obedecía a la preexistente debilidad del tejido productivo local, al hecho de que el empleo generado por MAGSA -si bien escaso- constituía la principal o única fuente de sustento del $20 \%$ de las familias de Andacollo y Huinganco (DIARIO LA MAÑANA DE NEUQUÉN, 2016) o que la actividad de la firma repercutía en diversas actividades -estaciones de expendio de combustible, hoteles, proveedores de alimentos, servicios mecánicos, etc.- (VELÁZQUEZ, 2009). Sin embargo, esa interpretación sería sesgada e incompleta si no se considerara la necesidad del capital de identificar a la población con el modelo hegemónico, una desapropiación epistémica, cultural y biopolítica (MACHADO ARÁOZ, 2013) basada en la colonización de las consciencias con el argumento de que la actividad es el único camino posible para alcanzar el 'progreso'.

En ese marco, los programas de Responsabilidad Social Empresaria (RSE) de MAGSA contribuyeron a forjar una psicoesfera (SANTOS, 1996), es decir, una narrativa o fábula que, mediante la persuasión, la manipulación y la operatividad simbólica, asegurara cierto consenso social respecto de la necesidad e inevitabilidad de adoptar y continuar el modelo dominante de modernización (SILVEIRA, 1999). Tentados por la posibilidad de insertarse laboralmente en la explotación minera, numerosos jóvenes abandonaron la escuela o bien desistieron de emigrar para realizar estudios superiores, mientras que varios pobladores e instituciones recurrieron a MAGSA para solicitar financiamiento de proyectos y auxilio económico (VELÁZQUEZ, 2009). Propagando la falacia de que los intereses egoístas de los agentes hegemónicos eran asimilables al bien común, estas situaciones no hicieron sino reforzar la extorsiva posición de dominio asumida por la firma global.

Obstando el escaso empleo directo generado, otros rasgos a destacar atañen al origen extrarregional de buena parte de los obreros de MAGSA y las estrategias de superexplotación y precarización de la fuerza laboral. Si bien la empresa sostenía que el $73 \%$ de sus trabajadores provenía de Andacollo y Huinganco (DIARIO LA MAÑANA DE NEUQUÉN, 2009), otros informes destacaban la gran incidencia de personal extranjero -sobre todo chileno-, con predominio absoluto en el caso de los puestos jerárquicos (NOYA, 2015). Los niveles de informalidad, precarización y terciarización laboral eran altos, siendo frecuente el despido y posterior re-contratación de operarios, así como también las denuncias por parte de los trabajadores debido a la ausencia de equipamiento e indumentaria de seguridad y las 
políticas de despidos arbitrarios ante protestas o intentos de sindicalización (VELÁZQUEZ, 2009; DIARIO CLARÍN, 2014). En relación a lo anterior, cabe mencionar otro mecanismo de acumulación por desposesión identificado por la literatura: la persistencia de ciertas formas de esclavitud (HARVEY, 2004). Así lo sugiere el frustrado y nunca aclarado intento de ingreso ilegal al país de siete ciudadanos chinos por el paso fronterizo Pino Hachado a bordo de un camión que prestaba servicio a MAGSA, un hecho que la prensa escrita relacionó con la trata de personas y el reclutamiento de fuerza de trabajo para las minas de Andacollo, y que fuera vehementemente negado por la compañía (DIARIO RÍO NEGRO, 2009b; 2009c).

Sobresalía también la superexplotación laboral basada en el aumento de plusvalía vía la reducción de la remuneración del obrero por debajo del costo de reproducción de su fuerza de trabajo (MARINI, 1991). Respecto de esta última cuestión, las remuneraciones de un obrero de MAGSA ascendían a 10.000 pesos en 2015 (DURÁN, 2015), situándose un 48,5\% y un 70,3\% por debajo de la media salarial nacional (19.399 pesos) y provincial (33.657 pesos) correspondiente al segundo trimestre de ese mismo año; por añadidura, dicho salario era casi cinco veces inferior a la remuneración promedio pagada por el sector minero metalífero en el país (48.493 pesos) (INDEC, 2015), revelando así una lógica de acumulación claramente basada en la expropiación al obrero de su capacidad de consumo (MARINI, 1991).

No obstante la lógica corporativa de sofocar cualquier contra-racionalidad que cuestionara su hegemonía, la política laboral de MAGSA desencadenó importantes conflictos sociales. Se destacan en ese sentido las huelgas desatadas en 2014 debido a salarios y aguinaldos adeudados (DIARIO CLARÍN, 2014), así como también las protestas, el bloqueo de puentes y caminos y las movilizaciones a la capital provincial derivadas del abandono de la explotación a comienzos de 2015. Lejos de remitir, estos conflictos recrudecieron durante los años siguientes con la adjudicación de la concesión a Trident Southern Explorations, debido a la negativa de la firma a re-contratar a la totalidad de la plantilla laboral dejada por su antecesora y reconocer su antigüedad y categoría, incumpliendo así con los compromisos asumidos con el gobierno neuquino (CALDUCCI, 2016; DIARIO RÍO NEGRO, 2017a; 2017b).

El Estado como garante de la acumulación por desposesión: la expropiación políticoeconómica 
Siguiendo a Amin (1975), las relaciones de transferencia de valor entre la periferia y el centro del sistema capitalista constituyen la esencia del problema de la acumulación a escala mundial. Así pues, la sangría de recursos financieros y valores de cambio desde las operaciones extractivas de los territorios periféricos hacia los centros mundiales de poder y riqueza es tanto la dimensión más antigua y burda del colonialismo como una de las dinámicas más importantes de la desposesión, resultando una función estructuralmente decisiva para la recomposición de los procesos de acumulación a escala global (MACHADO ARÁOZ, 2010). Lejos de limitarse a satisfacer las necesidades de consumo suntuario, preservación del valor del capital y abastecimiento de la industria tecnológica de punta del centro del sistema, la expoliación de los minerales metalíferos de la periferia también genera ganancias extraordinarias para las firmas globales. Estas rentas diferenciales a escala internacional se basan en la mercantilización y usurpación (legal e ilegal) de recursos públicos, un despojo que, por acción u omisión, es permitido y alentado por el propio Estado.

Operando como creadoras de territorio, las normas desempeñan aquí un papel estratégico, toda vez que producen y transforman el orden socio-espacial (SILVEIRA, 2000) diferenciando a los lugares según su productividad espacial, esto es, según su capacidad de ofrecer rentabilidad a las inversiones mediante condiciones técnicas (equipamientos, infraestructura, accesibilidad) y organizacionales (leyes, impuestos, etc.) (SANTOS, 1996). Orientadas a satisfacer exigencias externas, esas normas son el emergente de reformas institucionales sistemáticamente orientadas a recomponer la tasa de ganancia empresarial a través de una producción política de rentabilidad (MACHADO ARÁOZ, 2010).

Nacida durante el auge neoliberal de la década de 1990 y perfeccionada a comienzos del Siglo XXI por el neo-desarrollismo primero y el neo-conservadurismo después, la legislación minera actualmente vigente en Argentina es un claro ejemplo de estas dinámicas expropiatorias. Auxiliado por créditos del Banco Mundial, el gobierno nacional diseñó un andamiaje jurídico extremadamente favorable para la actividad, condensado en la Ley de Inversiones Mineras, la Ley de Reordenamiento Minero, el Acuerdo Federal Minero y la reformulación del Código de Minería. Esta nueva legislación contempla numerosas ventajas fiscales, arancelarias, tributarias, comerciales, financieras y políticas, tales como estabilidad fiscal por 30 años, desgravación de las importaciones de insumos y bienes de capital (arancel 0\%), reembolso del Impuesto al Valor Agregado (IVA), doble deducción de costos de exploración, eliminación de gravámenes y tasas municipales, regalías provinciales situadas en 
el orden de apenas el 3\% (como máximo) del valor de producción en boca de mina y exención del Impuesto al Cheque, a los Sellos, a los Combustibles y a la Ganancia Mínima Presunta.

Posteriormente el Estado ofreció nuevas ventajas, como los permisos para exportar y remitir utilidades al exterior sin pagar impuestos y utilizar cuentas off shore como base para activos financieros y plazas de depósito para divisas, la exención del IVA y el Impuesto a Créditos y Débitos Bancarios, la deducción del Impuesto a las Ganancias, el financiamiento del Programa de Gestión Ambiental Minera y la eliminación de las retenciones a las exportaciones. El apoyo incondicional al sector es una indiscutible política de Estado, como lo demuestra la creación de la Organización Federal de Estados Mineros (OFEMI), que aglutina a las provincias donde se desarrollan actividades de exploración y explotación.

Ocasionando la transferencia de una incalculable y multimillonaria masa de recursos desde el erario público hacia las arcas de las mineras transnacionales, las reformas normativoinstitucionales más arriba citadas reflejan sólo aquella parte del saqueo que se produce por omisión, es decir, debido a la voluntaria renuncia del Estado a percibir ingresos por conceptos que sí se aplican a la inmensa mayoría de las actividades económicas del país. Mención aparte requieren las expropiaciones económicas generadas por la acción del Estado y el capital, las cuales asumen una particular e insoslayable relevancia en el caso bajo estudio, formando así un continuum de prácticas institucionales (legales) y corporativas (ilegales) de despojo.

Obstando el usufructo de las inmejorables condiciones pautadas por la legislación minera nacional, MAGSA recibió también sendos beneficios del gobierno provincial y municipal. La permanente estrategia extorsiva de la compañía determinó que en 2001 -año de la peor crisis social y económica de la historia argentina- el Estado neuquino le brindara subvenciones económicas y asistencia financiera para así garantizar la continuidad de la explotación del complejo minero e impedir que la firma prosiguiera con su política de despidos. El auxilio del Estado provincial implicó el suministro de de energía eléctrica a precio preferencial y el subsidio de las tasas de interés correspondientes a un crédito de 2,1 millones de dólares, a cambio de que MAGSA se comprometiera a contratar fuerza de trabajo local -en ese momento la empresa empleaba a apenas 30 operarios neuquinos- y suplantara la remesa en bruto a Chile del concentrado mineral por la instalación en Andacollo de una planta de fundición -algo jamás cumplido por la firma- (VELÁZQUEZ, 2009; DIARIO CLARÍN, 2014; DIARIO RÍO NEGRO, 2003). Basada en la externalización de los costos de producción privados y la socialización del riesgo empresario, esta expropiación de recursos públicos para 
beneficio corporativo corrobora que la acumulación por desposesión es, como sugiere Harvey (2004), un proceso activamente respaldado y fomentado por el Estado a distintas escalas.

Este fenómeno suele agudizarse en épocas de crisis, cuando las multimillonarias ganancias corporativas rutinariamente embolsadas en tiempos de bonanza pasan a ser engrosadas por la estrategia empresarial de descargar en el Estado los costos de la coyuntura. Aduciendo la caída del precio internacional del oro $^{6}$ y su propia insolvencia patrimonial, MAGSA abandonó las minas a comienzos de 2015, adeudando varios meses de salarios ${ }^{7}$, pagos a proveedores y regalías mineras (DIARIO RÍO NEGRO, 2015c). Como resultado, el gobierno provincial debió invertir más de 45 millones de pesos en abonar salarios adeudados, incorporar a gran parte de los obreros cesantes a la plantilla laboral de CORMINE, mantener las instalaciones y equipamiento del complejo y remediar algunos pasivos ambientales, utilizando a ex-trabajadores mineros para apuntalar roca de los socavones para evitar posibles derrumbes e impedir que el material contaminado de las fracturas y el dique de colas llegara a los cursos de agua (DURÁN, 2015; EL INVERSOR ENERGÉTICO, 2016). Al ser recontratados por media jornada, los obreros recibían el 65\% del salario que pagaba la minera el $50 \%$ era aportado por CORMINE, y el 15\%, por los municipios de Andacollo y Huinganco-, lo cual desencadenó álgidos conflictos sociales y políticos, dado que los trabajadores reclamaban que la provincia les abonara los salarios completos, en una puja que finalmente se zanjó a favor de los obreros (DURÁN, 2015; DIARIO RÍO NEGRO, 2015c).

A lo anterior se añaden los mecanismos ilegales de despojo implementados por MAGSA durante los diecisiete años que explotó las minas neuquinas. Ejemplo de ello fueron las poco transparentes condiciones de transporte y exportación a Chile de las riquezas extraídas, denunciándose la sub-declaración del contenido, volumen y valor de la carga, el ocultamiento de oro y otros metales en vehículos terrestres, el traslado de la producción en horarios nocturnos para evitar inspecciones y las autorizaciones administrativas irregulares para cruzar la frontera trasandina dispuestas por personal no calificado para tal tarea ${ }^{8}$ (VELÁZQUEZ, 2009).

\footnotetext{
${ }^{6}$ Un argumento poco creíble, teniendo en cuenta que la onza de oro cotizaba a 300 dólares cuando MAGSA comenzó a explotar el complejo minero y a 1.350 dólares cuando lo abandonó.

${ }^{7}$ Esta situación derivó en una demanda judicial de los trabajadores contra MAGSA por 5 millones de pesos en concepto de salarios adeudados, cifra que con los intereses se elevó a 10 millones de pesos.

${ }^{8}$ Se ha denunciado que la empresa exportaba oro ilegalmente ocultándolo en para-golpes de camionetas y fondos de barriles, y que la carga cruzaba la frontera con papeles firmados por empleados privados de seguridad.
} 
En ese contexto, la connivencia del poder político provincial y local reforzaba el ya de por sí amplio respaldo jurídico y moral a la acumulación por desposesión, a tal punto que el Estado operaba como garante de las prácticas corporativas ilegales brindando impunidad y legitimación al despojo derivado de las mismas. Sobresalían en ese sentido casos como el secuestro por parte de Gendarmería de los camiones de MAGSA debido a la ausencia de la documentación correspondiente y la posterior liberación de dichos vehículos por orden expresa del gobierno provincial, así como también la alianza estratégica de la firma minera con los concejales del partido gobernante (VELÁZQUEZ, 2009) y la declaración de interés municipal de la actividad de la empresa por parte del intendente de Andacollo, quien resaltó las inversiones y empleos generados por MAGSA luego de que pobladores de Huaraco y Huinganco denunciaran que la compañía descargaba sustancias contaminantes en las cercanías de la toma de agua del pueblo (DIARIO LA MAÑANA DE NEUQUÉN, 2009).

\section{Expropiación ecológica y avasallamiento de derechos: apropiación diferencial de recursos hídricos y contaminación ambiental}

Otros mecanismos de acumulación por desposesión intrínsecos al período histórico actual atañen a la mercantilización de la naturaleza en todas sus formas y al creciente y alarmante deterioro del hábitat, dos fenómenos que han provocado la merma de los bienes hasta ahora comunes del entorno global (tierra, agua, aire, etc.) (HARVEY, 2004). Como resultado, hitos como la desaparición de los bosques tropicales, la polución del aire, el agua y el suelo, y la obvia degradación de los espacios sociales de vida forman parte del proceso de destrucción generalizada de los bienes comunes del planeta (MIDNIGHT NOTES COLLECTIVE, 2001). La expropiación ecológica como modalidad de acumulación por desposesión es especialmente patente en el caso de la mega-minería metalífera, una actividad con fuerte gravitación sobre la destrucción del paisaje, la pérdida de biodiversidad, la polución atmosférica, la alteración del ciclo hidrológico, la escasez y consecuente competencia por el uso del agua y la contaminación de recursos edáficos e hídricos. Como consecuencia, la dimensión ecológica es el aspecto geopolíticamente más relevante y la consecuencia más grave de las dinámicas expropiatorias asociadas al modelo minero, toda vez que implica el despojo de los bienes y servicios comunes de la naturaleza que nos hacen cuerpos (MACHADO ARÁOZ, 2010). 
El agua es un insumo clave para los procesos extractivos de la minería metálica a gran escala, sobre todo en el caso de la explotación a cielo abierto (open pit) debido a la baja ley de los minerales y el alto nivel de diseminación de los mismos. Sin embargo, y aunque lo haga en menor proporción que la modalidad anterior, la minería subterránea también consume grandes volúmenes de recursos hídricos en los procesos de concentración por flotación. Si bien para el caso bajo estudio no se disponen de cifras estimativas, vale la pena advertir que en Argentina la mega-minería metalífera genera una importantísima huella hídrica, que fluctúa (según el yacimiento) entre 1.000 y 50.000 litros de agua por onza troy de oro 9 (GÓMEZ LENDE, 2015a). Con los metales extraídos, miles de millones de litros de agua migran al exterior, estrategia imperialista que permite a los países importadores de metales y las naciones de origen de las mineras externalizar costos ambientales, obtener un significativo ahorro de agua dentro de sus propias fronteras, colocar vastas reservas de agua dulce bajo el control del capital y desarrollar un desmesurado (y a menudo gratuito) consumo hídrico en la periferia.

Con la privatización de la fábrica de agua dulce cordillerana dictada por el tratado chileno-argentino de integración minera, el capital pasó a desplegar estrategias predatorias de apropiación diferencial y acaparamiento de recursos hídricos que desataron agudos conflictos socio-territoriales. El caso de MAGSA no fue la excepción a la regla. A finales de 2003, la compañía colocó una compuerta en el arroyo Huaraco que obstruía la escorrentía hacia el canal de riego utilizado por agricultores y pobladores del paraje homónimo; meses después, y arguyendo que el caudal de dicho curso fluvial era insuficiente para el tratamiento del oro, la firma se arrogó el derecho de utilizar maquinaria pesada para desviar el cauce del arroyo y así disponer de más agua, dejando completamente privada del vital elemento a toda la población (DIARIO RÍO NEGRO, 2004).

Acusando a MAGSA de incumplir su compromiso previo de garantizar un caudal mínimo de 11 litros por segundo aguas abajo de las minas, la comunidad local reclamó la intervención de la Dirección Provincial de Recursos Hídricos y amenazó con demandar judicialmente a la compañía. No obstante, las tácticas de disciplinamiento y control social de la minera y su constante amenaza de abandonar la explotación zanjaron el conflicto rápida e insólitamente: en vez de liberar el curso del arroyo, MAGSA comenzó a abastecer a

\footnotetext{
${ }^{9}$ La onza troy, una medida de volumen habitualmente utilizada en joyería, es equivalente a 31,1 gramos.
} 
pobladores y regantes con camiones de agua, solución mucho más barata que invertir 500.000 pesos en instalar una bomba para traer agua del cercano Río Neuquén (VELÁZQUEZ, 2009).

Corroborando la tesis de Machado Aráoz (2010) de que el ingente consumo hídrico de las transnacionales mineras inexorablemente acaba conduciendo a la expropiación a las poblaciones locales de las dosis necesarias de agua que los convierten en cuerpos-sujetos, lo anterior es un claro ejemplo empírico acerca de cómo el orden global produce desorden local al imponer una producción limitada de racionalidad que beneficia a los agentes hegemónicos y una producción amplia de escasez que perjudica a la mayoría, colocando a la lógica del capital por encima de la satisfacción de las necesidades humanas más básicas y elementales.

Por añadidura, los cercamientos derivados del despojo de los recursos hídricos domésticos acababan solapándose a los cercamientos producidos por distintas formas de contaminación ambiental. Sobresalía en ese sentido la destrucción de cerros a raíz tanto del trazado de caminos como de la propia explotación minera, así como también las constantes explosiones y voladuras, en algunos casos realizadas a apenas 150 metros de las viviendas de los pobladores de Huinganco, infringiendo así una ordenanza local que prohibía desarrollar esas actividades a menos de 1 kilómetro de las cañerías de gas y el ejido municipal ${ }^{10}$ (DIARIO RÍO NEGRO, 2012). Dado que MAGSA operaba durante las 24 horas del día, esta cuestión desencadenó agudos conflictos con la población urbana, los propietarios de campos y los puesteros rurales, cuyas fuertes protestas obligaron a la compañía minera a evitar las detonaciones nocturnas, usar explosivos de menor impacto, informar el calendario de voladuras y prevenir la onda expansiva (DIARIO RÍO NEGRO, 2015e). Sin embargo, estas restricciones no implicaron respetar la distancia reglamentaria dispuesta por la normativa local, trasgresión justificada por la autoridad minera provincial con el falaz argumento de que las explosiones provocaban sólo ruido, pero no vibraciones en la zona urbana (DIARIO RÍO NEGRO, 2012).

Mención aparte requieren los numerosos incidentes de polución ambiental generados por la compañía minera durante el período 2003-2012, entre los cuales se destacaban los derrames de relaves, el rebalse de piletas de contención, las fisuras y consiguientes filtraciones rutinarias de los diques de colas, los vertidos intermitentes de la planta de tratamiento de minerales y los derrames de gasoil y efluentes tóxicos, todos ellos afectando tanto al arroyo Huaraco y el canal de riego homónimo como al arroyo Torreón (DIARIO RÍO

\footnotetext{
${ }^{10}$ La firma fue notificada de la prohibición, pero continuó infringiendo la ordenanza municipal.
} 
NEGRO, 2008; 2009; VELÁZQUEZ, 2009; BERDUGO, 2014). Dado que la contaminación se extendía aguas abajo perjudicando a 40 familias rurales dedicadas a la producción de cultivos para autoconsumo, la crianza de ganado y la elaboración de alimentos para la venta en Andacollo y Huinganco, estas reiteradas (y casi cotidianas) situaciones pusieron en jaque la reproducción de las economías locales pre-capitalistas de subsistencia, provocando la rotura de alambrados, el secado de árboles, la mortandad animal y la pérdida de frutales, producción hortícola y sembradíos. Asimismo, la polución rutinaria del canal de riego -que había sido construido por los propios pobladores- implicó que la corrosión destruyera electrodomésticos y cañerías de las viviendas más cercanas a las minas. Como resultado, en 2006 la empresa fue obligada a proveer permanentemente agua mineral para consumo a las familias afectadas (DIARIO RÍO NEGRO, 2008; 2009; DIARIO LA MAÑANA DE NEUQUÉN, 2009).

Ante la gravedad de la situación, las comunidades locales desafiaron la racionalidad hegemónica de la firma global a través del ejercicio de contra-racionalidades, entablando numerosas denuncias legales por daños y perjuicios contra la compañía minera (DIARIO RÍO NEGRO, 2009d; 2009e). Sin embargo, estos conflictos jurídicos y socio-ambientales fueron parcialmente desactivados por el capital a partir de una contra-ofensiva basada en el amedrentamiento y la extorsión, toda vez que la empresa advirtió que despediría a sus operarios y se retiraría del lugar si continuaban los cuestionamientos; concomitantemente, aquellos dirigentes sociales, sindicales y políticos que procuraron organizar asambleas populares que contrarrestaran el poderío de MAGSA fueron amenazados e incluso expulsados del pueblo (VELÁZQUEZ, 2009). Por añadidura, algunas de las familias campesinas más afectadas por la polución decidieron abandonar el lugar (DIARIO RÍO NEGRO, 2009e).

Otra cuestión digna de consideración es, finalmente, la desposesión del derecho a la salud (GÓMEZ LENDE, 2015b). La minería aurífera a gran escala siempre requiere lixiviar y concentrar el oro extraído utilizando grandes cantidades de agentes químicos de alta peligrosidad, generalmente mercurio o cianuro de sodio. En este caso, las comunidades locales denunciaron que MAGSA utilizaba mercurio, algo que fue repetidamente negado por la empresa, aunque sin jamás informar qué productos usaba para procesar el mineral. Asimismo, nunca se conocieron los resultados de las muestras tomadas de los derrames, en un confuso marco donde el poder político minimizaba la gravedad de los incidentes ${ }^{11}$ y

${ }^{11}$ Paradójicamente, estos hechos fueron ratificados por el gobierno provincial en 2015, cuando MAGSA abandonó la explotación. Según un informe técnico, se detectaron excesos en la cota del dique de cola, manejos 
Gendarmería exhortaba a los habitantes de Huinganco y Huaraco a no consumir el agua del canal (VELÁZQUEZ, 2009). La firma también rebatió la acusación de contaminación hídrica con arsénico por drenajes ácidos de roca argumentando que la presencia de este mineral se debía a la polución natural de las napas, ignorando así convenientemente el hecho de que el norte neuquino ni siquiera figura en los mapas nacionales de hidro-arsenicismo.

Lo cierto es que, poco después del inicio de la explotación minera -y en un contexto signado por denuncias de que la firma volcaba sustancias contaminantes en las cercanías de la toma de agua del pueblo-, el hospital local comenzó a reportar un número creciente de casos de diarreas, vómitos y gastroenteritis; posteriormente, se detectaron patologías graves (entre ellas, cáncer) entre los integrantes de la familia rural más afectada por los derrames y vertidos tóxicos del dique de colas de MAGSA, los cuales residían a apenas 300 metros de la planta de tratamiento del concentrado mineral (VELÁZQUEZ, 2009; DIARIO RÍO NEGRO, 2009e).

\section{CONSIDERACIONES FINALES}

De acuerdo a la literatura, la gran empresa transnacional y sus estrategias de acumulación por desposesión operan como vectores del orden global que, al imponer la racionalidad hegemónica del capital con respecto a cómo el territorio es usado, acaban perturbando la vida de relaciones del lugar. El relativamente reciente resurgimiento de la minería aurífera en el norte neuquino no evade esa ley general, corroborando la íntima relación existente entre desorden local, conflicto socio-espacial y dinámicas expropiatorias basadas en la profundización de la privatización y mercantilización de lo común. De hecho, el caso aquí estudiado reúne buena parte de los mecanismos de acumulación por desposesión reconocidos por la bibliografía, tales como la privatización y extranjerización de la tierra, el subsuelo y los recursos minerales, el cercenamiento de los derechos de libre circulación territorial para los agentes sociales subalternizados, la persistencia de ciertas formas de esclavitud, la mercantilización de la naturaleza, la degradación del patrimonio ambiental y la 
erosión de las formas de producción precapitalistas. Por añadidura, el tejido socio-productivo local ha sido rearticulado al mercado mundial bajo la racionalidad de economía de enclave diseñada por el espacio de flujos corporativos y el circuito espacial de producción de la firma global, no siendo desplazado sino más bien cooptado por la lógica del capital. Asimismo, y a pesar del magro empleo directo generado y los elevados niveles de precarización laboral, la firma global colonizó simbólicamente las consciencias al persuadir a una sociedad pastoril y tradicionalmente dependiente del empleo público acerca de la indispensabilidad de su presencia, lo cual le permitió desplegar diversas formas de control y disciplinamiento social.

Ora vía reformas institucionales basadas en la producción política de rentabilidad exenciones, subsidios, socialización del 'riesgo' empresario, etc.-, ora a través del impune recurso del capital a prácticas jurídicamente ilícitas, el auge de la minería metálica en el norte neuquino ha conducido también al enriquecimiento corporativo a expensas del Estado, un proceso basado en la expropiación de activos públicos y la consiguiente transferencia de grandes masas de valor al exterior. En el plano socio-ecológico, sobresalen también hitos como la apropiación diferencial del agua en tanto que bien común no renovable básico para la vida, su drenaje al exterior, la producción de cercamientos asociados a las prácticas corporativas de acaparamiento, dilapidación y restricción del libre acceso al recurso, la articulación de las reservas hídricas locales a las cadenas verticales de valor de la firma global y la alienación de las comunidades locales respecto de sus derechos más elementales. En la misma línea se sitúan los episodios de contaminación ambiental y desposesión del derecho a la salud, los cuales revelan los ribetes más extremos y perversos de la contradicción dialéctica fundamental entre orden global y desorden local. En este último sentido, cabe destacar que el caso estudiado no muestra una erosión de economías pre-capitalistas asociada a procesos históricos típicamente mencionados por la literatura (por ejemplo, proletarización del campesinado), sino más bien ligada a la supresión de rugosidades por cercamientos ambientales que despojan y destruyen bienes comunes que permiten la reproducción social.

Si bien las dinámicas expropiatorias puestas en juego por la lógica hegemónica del capital y la consiguiente producción de desorden local generaron agudos conflictos laborales y ambientales, las contra-racionalidades desplegadas por los grupos subalternizados fueron en gran medida infructuosas, especialmente en el plano ambiental. La razón que explica este hecho atañe a los variados mecanismos de omisión, legitimación y protección que el aparato político proporcionó a la firma global, en un marco donde tanto el Estado provincial como el 
local respaldaron las prácticas legales e ilegales de despojo llevadas a cabo por la compañía minera. En resumidas cuentas, queda claro que la reactivación de la minería metalífera en el norte neuquino ha establecido un orden espacial o modelo dominante de uso del territorio que, funcional a los intereses de los actores hegemónicos, resultó absolutamente irracional para la sociedad local al no satisfacer -e incluso atentar contra- sus necesidades más esenciales.

\section{REFERENCIAS BIBLIOGRÁFICAS}

AMIN, S. La acumulación a escala mundial: crítica a la teoría del subdesarrollo. Buenos Aires: Siglo XXI, 1975.

ANTONELLI, M. Mega-minería transnacional y riqueza bruta. Invención de un paradigma y continuidades del principio de acumulación. Puente@Europa, n. 2, v. VIII, p. 52-62, Buenos Aires, 2010.

BERDUGO, F. La mina de Andacollo: derrames y fisuras de la minería segura. 1 de abril de 2014. Disponible en: <http://noalamina.org/argentina/neuquen/item/12417-la-mina-deandacollo-derrames-y-fisuras-de-la-mineria-segura>. Acceso en: 22 de octubre de 2017.

BERTANI, L. A. Evaluación geoecológica de los paisajes del Departamento Minas (Provincia de Neuquén), para el estudio de la degradación de la tierra. Tesis (Doctorado en Geografía), 2011. Universidad Nacional de La Plata, La Plata, 2011.

CAC. Perfiles exportadores provinciales 2015. Buenos Aires: Cámara Argentina del Comercio, 2016.

CALDUCCI, A. L. Andacollo: la nueva minera promete crear 500 empleos. Diario La Mañana de Neuquén, 15 de septiembre de 2016. Disponible en: $<$ https://www.Imneuquen.com/andacollo-la-nueva-minera-promete-crear-500-empleosn526344>. Acceso en: 15 de noviembre de 2017.

COLANTUONO, M. R. Neuquén, una Geografía abierta. Buenos Aires: Grupo Hache, 1995.

DE ANGELIS, M. Marx and primitive accumulation: The continuous character of capital's 'enclosures'. The Commoner, n. 2, 2001. Disponible en: <http://www.commoner.org.uk/02midnight.pdf >. Acceso en: 22 de octubre de 2017.

DIARIO CLARÍN. Los trabajadores de la minera Andacollo Gold cumplen una semana de paro. 14 de julio de 2014. Disponible en: <https://www.clarin.com/economia/neuquenandacollo_gold-mineria-conflicto_0_r1WQbliqPQ1.html>. Acceso en: 15 de noviembre de 2017.

DIARIO LA MAÑANA DE NEUQUÉN. Respaldo municipal a la minera Andacollo Gold. 2009. Disponible en: <http://www.petrolnews.net/noticia.php?\&r=12121>. Acceso en: 15 de noviembre de 2017.

DIARIO LA MAÑANA DE NEUQUÉN. Andacollo: la mina vuelve otra vez a manos de un privado. 27 de agosto de 2016. Disponible en: <https://www.Imneuquen.com/andacollo-lamina-vuelve-manos-un-privado-n524377>. Acceso en: 15 de noviembre de 2017.

DIARIO RÍO NEGRO. La minera Andacollo exporta oro a Chile. 28 de enero de 2003. Disponible en: 〈http://www1.rionegro.com.ar//arch200301/r28a14.html >. Acceso en: 17 de noviembre de 2017. 
DIARIO RÍO NEGRO. Aseguran que una minera dejó sin agua a un paraje. 12 de febrero de 2004. Disponible en: 〈http://www1.rionegro.com.ar/arch200402/12/m12s11.php>. Acceso en: 17 de noviembre de 2017.

DIARIO RÍO NEGRO. Preocupa el derrame a un canal desde la minera de Andacollo. 5 de septiembre de 2008. Disponible en: <http://www.rionegro.com.ar/sociedad/preocupa-elderrame-a-un-canal-desde-la-minera-de-andacollo-CWHRN1252119163169>. Acceso en: 17 de noviembre de 2017.

DIARIO RÍO NEGRO. Neuquén exportó casi 200.000 toneladas de minerales en 2008. 3 de marzo de 2009 (a). Disponible en: <http://www.rionegro.com.ar/region/neuquen-exporto-casi200-000-toneladas-de-minerales-en-2008-AXHRN1236046939188>. Acceso en: 15 de noviembre de 2017.

DIARIO RÍO NEGRO. Intentaron ingresar ilegalmente a siete chinos. 10 de noviembre de 2009 (b). Disponible en: <http://www.rionegro.com.ar/policiales/intentaron-ingresarilegalmente-a-siete-chinos-DJHRN1257821540144>. Acceso en: 15 de noviembre de 2017.

DIARIO RÍO NEGRO. La minera Andacollo Gold negó relación con los chinos. 13 de noviembre de 2009 (c). Disponible en: <http://www.rionegro.com.ar/policiales/la-mineraandacollo-gold-nego-relacion-con-los-chinos-NGHRN1258079249158>. Acceso en: 15 de noviembre de 2017.

DIARIO RÍO NEGRO. Denuncian contaminación minera. 14 de mayo de 2009 (c). Disponible en: <http://www.rionegro.com.ar/sociedad/denuncian-contaminacion-mineraYSHRN124226964387>. Acceso en: 17 de noviembre de 2017.

DIARIO RÍO NEGRO. Anuncian demanda a una minera. 27 de febrero de 2009 (d). Disponible en: <http://www.rionegro.com.ar/sociedad/anuncian-demanda-a-una-mineraEVHRN123570235046>. Acceso en: 17 de noviembre de 2017.

DIARIO RÍO NEGRO. Neuquén vive una producción minera en alza. 7 de mayo de 2011. Disponible en: <http://www.rionegro.com.ar/sociedad/neuquen-vive-una-produccion-mineraen-alza-OWRN_617988>. Acceso en: 17 de noviembre de 2017.

DIARIO RÍO NEGRO. Denuncian explosiones de minera cerca de Huinganco. 4 de octubre de 2012. Disponible en: <http://www.rionegro.com.ar/portada/denuncian-explosiones-deminera-cerca-de-huinganco-KGRN_978121>. Acceso en: 17 de noviembre de 2017.

DIARIO RÍO NEGRO. De la vid a las galerías. 25 de enero de 2015 (a). Disponible en: <http://www.rionegro.com.ar/region/de-la-vid-a-las-galerias-XPRN_5735798>. Acceso en: 17 de noviembre de 2017.

DIARIO RÍO NEGRO. Corte de mineros de Andacollo complica al norte. 12 de abril de 2015 (b). Disponible en: <http://www.rionegro.com.ar/region/corte-de-mineros-de-andacollocomplica-al-norte-NURN_7253108>. Acceso en: 17 de noviembre de 2017.

DIARIO RÍO NEGRO. Andacollo Gold, al borde de perder la concesión. 25 de enero de 2015 (c). Disponible en: <http://www.rionegro.com.ar/region/andacollo-gold-al-borde-de-perderla-concesion-GPRN_5735781>. Acceso en: 17 de noviembre de 2017.

DIARIO RÍO NEGRO. El ambiente en la mira. 25 de enero de 2015 (d). Disponible en: <http://www.rionegro.com.ar/region/el-ambiente-en-la-mira-GPRN_5735790>. Acceso en: 17 de noviembre de 2017.

DIARIO RÍO NEGRO. Negociaciones hay, pero no acuerdan soluciones en el conflicto minero. 19 de julio de 2017 (a). Disponible en: <http://www.rionegro.com.ar/region/negociaciones-hay-pero-no-acuerdan-soluciones-en-elconflicto-minero-MG3190284>. Acceso en: 17 de noviembre de 2017.

DIARIO RÍO NEGRO. Amenazan con despedir a los mineros si mantienen la protesta. 15 de julio de 2017 (b). Disponible en: <http://www.rionegro.com.ar/region/amenazan-con- 
despedir-a-los-mineros-si-mantienen-la-protesta-GN3168282 >. Acceso en: 17 de noviembre de 2017.

DINREP. Necesidades Básicas Insatisfechas (NBI), Información censal del año 2010 (versión ampliada con datos departamentales). Buenos Aires: DINREP-Ministerio de Economía y Finanzas Públicas de la Nación, 2014.

DURÁN, A. Andacollo, un pueblo atado al destino de la minería. Diario Río Negro, 15 de abril de 2015. Disponible en: <http://www.rionegro.com.ar/region/andacollo-un-puebloatado-al-destino-de-la-mineria-FSRN_7054745>. Acceso en: 17 de noviembre de 2017.

EL INVERSOR ENERGÉTICO. (2016). Hay cuatro interesados en reactivar una mina de oro en Neuquén. Disponible en: <http://www.inversorenergetico.com.ar/hay-cuatro-interesadosen-reactivar-una-mina-de-oro-en-neuquen/>. Acceso en: 8 de junio de 2017.

GARIBAY OROZCO, C. Paisajes mineros de acumulación por desposesión campesina en el México actual. In: DELGADO RAMOS, G. C. (Ed.). Ecología política de la minería en América Latina. Aspectos socioeconómicos, legales y ambientales de la mega minería. México, D.F.: UNAM, 2010.

GIRAUD, M.; RUZ, G. Chile-Argentina: una cordillera enajenada. Políticas y perspectivas de la minería. Realidad Económica, n. 248, p. 11-40, Buenos Aires, 2009.

GÓMEZ LENDE, S. Orden global y acumulación por desposesión. La exportación de 'agua virtual' y la huella hídrica de la minería metalífera en la Argentina (1997-2014). Revista de Estudos Ambientais, n. 17, v. 2, p. 6-28, Blumenau, 2015a.

GÓMEZ LENDE, S. Acumulación por desposesión y conflictos espaciales. La minería metalífera en la Argentina contemporánea. Saarbrücken: Editorial Académica Española, 2015 b.

HARVEY, D. EI nuevo imperialismo. Madrid: Akal, 2004.

IGN. (s/f). Provincia del Neuquén. Mapa político. Instituto Geográfico Nacional. Disponible en: http://www.ign.gob.ar/images/MapasWeb/NEUQUEN/NEUQUEN-POLITICO-WEB.jpg

INDEC. Base de datos REDATAM. Censo 2010. Cuestionario ampliado. Resultados básicos. Buenos Aires: Instituto Nacional de Estadística y Censos, 2013.

INDEC. Evolución de puestos de trabajo y promedios de remuneraciones y costo salarial de los asalariados registrados. Segundo trimestre 2015. Buenos Aires: Instituto Nacional de Estadística y Censos, 2015.

MACHADO ARÁOZ, H. El agua vale más que el oro. Grito de resistencia decolonial contra los nuevos dispositivos expropiatorios. In: DELGADO RAMOS, G. C. (Ed.). Ecología política de la minería en América Latina. Aspectos socioeconómicos, legales y ambientales de la mega minería. México, D.F.: UNAM, 2010.

MACHADO ARÁOZ, H. Entre la fiebre del oro y las voladuras... Cuerpos y emociones en contextos de mineralización. Revista Latinoamericana de Estudios Sobre Cuerpos, Emociones y Sociedad, n. 11, n. 5, p. 21-33, Córdoba, 2013.

MANDEL, E. Tratado de economía marxista. México: Fondo de Cultura Económica, 1969. MARINI, R. M. Dialéctica de la dependencia. México: Ediciones Era, 1991.

MARX, K. El capital. México: Fondo de Cultura Económica, 1968.

MIDNIGHT NOTES COLLECTIVE. The new enclosures. The Commoner, n. 2, 2001. Disponible en: <http://www.commoner.org.uk/02deangelis.pdf >. Acceso en: 22 de octubre de 2017.

MORAES, A. C. R. Los circuitos espaciales de producción y los círculos de cooperación en el espacio. In: LIBERALI, A. M.; YANES, L. (Org.). Aportes para el estudio del espacio socioeconómico (III). Buenos Aires: El Coloquio, 1988. 
NOYA, N. Minera Andacollo Gold y la teoría del vampiro. 2015. Disponible en:

$<$ http://noalamina.org/argentina/neuquen/item/14045-minera-andacollo-gold-y-la-teoria-delvampiro>. Acceso en: 15 de noviembre de 2017.

OCMAL. Mapa de conflictos mineros en América Latina. 2017. Disponible en: $<$ http://www.conflictosmineros.net/>. Acceso en: 8 de junio de 2017.

ORTIZ, R. Las empresas transnacionales en la minería argentina: seguridad jurídica para las empresas, inseguridad ambiental e incumplimiento de los derechos para las comunidades locales. Buenos Aires: Programa de Vigilancia Social de las Empresas Transnacionales, 2008. PATNAIK, P. The economics of the new phase of imperialism. 2005. Disponible en: $<$ http://macroscan.com/archive/archive_analysis.htm.>. Acceso en: 8 de junio de 2017.

ROUX, R. Marx y la cuestión del despojo. Claves teóricas para iluminar un cambio de época. Herramienta, n. 38, Buenos Aires, 2007.

SÁNCHEZ, J-E. Espacio, economía y sociedad. Barcelona: Siglo XXI Editores, 1990.

SANTOS, M. A natureza do espaço. Técnica e tempo, razão e emoção. São Paulo: Hucitec, 1996.

SANTOS, M. Por uma outra globalização. Do pensamemto único ã consciência universal. Rio de Janeiro-São Paulo: Record.

SANTOS, M.; SILVEIRA, María Laura. O Brasil. Território e sociedade no início do século XXI. Rio de Janeiro-São Paulo: Record, 2001.

SAPAG, L. F. La miseria de los veranadores del Alto Neuquén, según Samuel "Chiche" Gelblung. Cuadernos de $\mathbf{H}$ ideas, v. 2, n. 2, 2012. Disponible en: $\langle$ http://perio.unlp.edu.ar/ojs/index.php/cps/article/view/1375>. Acceso en: 18 de octubre de 2017.

SILLA, R. Variaciones espaciales, temporales y estacionales de los crianceros del norte neuquino. Revista Transporte y Territorio, n.3, p. 3-22, Buenos Aires, 2010.

SILVEIRA, M. L. Um país, uma região. Fim de século e modernidades na Argentina. São Paulo: LABOPLAN-USP, 1999.

SILVEIRA, M. L. O espaço da globalização: usos diversos, comando único. In: SANTOS, M. (ed.). Cidadania e globalização. Bauru: Saraiva, 2000.

TETREAULT, D. Los mecanismos del imperialismo canadiense en el sector minero de América Latina. Estudios críticos del desarrollo, n. 3, v. 4, p. 191-215, Zacatecas, 2013.

VELÁZQUEZ, L. Oro y miedo en el lejano norte. 2009. http://www.8300.com.ar/2009/09/07/oro-y-miedo-en-el-lejano-norte/ Acceso en: 8 de junio de 2017.

Recebido em 15 de dezembro de 2017.

Aceito em 18 de março de 2018. 